\title{
BMJ Open Cross-sectional analysis on publication status and age representation of clinical studies addressing mechanical ventilation and ventilator-induced lung injury in infants and children
}

\author{
Christian Patry, ${ }^{1,2}$ Simon Kranig, ${ }^{3}$ Neysan Rafat, ${ }^{4}$ Thomas Schaible, ${ }^{4}$ \\ Burkhard Toenshoff, ${ }^{1}$ Georg F Hoffmann, ${ }^{1}$ Markus Ries ${ }^{5}$
}

To cite: Patry C, Kranig S, Rafat $\mathrm{N}$, et al. Cross-sectional analysis on publication status and age representation of clinical studies addressing mechanical ventilation and ventilator-induced lung injury in infants and children. BMJ Open 2018;8:e023524. doi:10.1136/ bmjopen-2018-023524

- Prepublication history and additional material for this paper are available online. To view these files, please visit the journal online (http://dx.doi. org/10.1136/bmjopen-2018023524).

CP and SK contributed equally.

Received 10 April 2018

Revised 10 September 2018

Accepted 18 September 2018

D) Check for updates

(c) Author(s) (or their employer(s)) 2018. Re-use permitted under CC BY-NC. No commercial re-use. See rights and permissions. Published by BMJ.

For numbered affiliations see end of article.

Correspondence to Dr Christian Patry; christian.patry@med.uniheidelberg.de

\section{ABSTRACT}

Objectives We determined the number and time-topublic availability of study results of published and unpublished clinical studies in paediatric mechanical ventilation (MV) and ventilator-induced lung injury (VILI), which were registered as completed on ClinicalTrials. gov. Furthermore, we explored the pattern of represented research study subtopics and the corresponding study populations.

Setting Literature search based on ClinicalTrials.gov, PubMed and Google Scholar from 9 July 2017 to 27 September 2017.

\section{Primary and secondary outcome}

measures Assessment, if studies included in our analysis had been published. Assessment of primary research focus, patient enrolment and age representation of the analysed studies.

Results We identified $n=109$ registered and completed clinical studies on paediatric MV and VILI (enrolment: 22233 participants). $71 \%$ were published, including data from 18647 subjects. $29 \%$ of studies were unpublished, containing data from 3586 subjects. Median time-topublic availability of study results was 22 (IQR, 12.8-41.5) months. The most important study subtopics were biophysical and technical aspects of MV (32 studies), administration of drugs to mitigate VILI through various mechanisms (40 studies) and diagnostic procedures (16 studies). $n=66 / 109$ (61\%) studies exclusively focused on children below 1 year of age and $n=2 / 109$ (2\%) exclusively on children between 1 and 14 years.

Conclusions One-third of clinical studies in paediatric MV and VILI registered as completed on ClinicalTrials. gov remained unpublished and contained data on 3586 study participants. The overall median time-to-public availability of study results was longer than the deadline of 12 months mandated by the Food and Drug Administration Amendment Act of 2007. Important and clinically relevant research study subtopics were represented in the research questions investigated in paediatric MV and VILI. The study population was skewed towards children younger than 1 year which indicates, that there is a substantial need for clinical VILI research in older children.

\section{Strengths and limitations of this study}

- This is the first study to coherently investigate publication status in clinical studies on paediatric invasive mechanical ventilation (MV) and ventilator-induced lung injury (VILI) in children of all ages.

- This study raises the awareness, that publication bias in paediatric research, which has been proposed by many recent publications, may also be present in paediatric MV research and thereby might affect clinical decision-making and outcome in critically ill children.

- The design of this study and the respective results allow to assess, if international measures, like the Food and Drug Administration Amendment Act from 2007, might have a positive impact on the time-topublic availability of study results in clinical paediatric MV and VILI research.

- As a limitation, our study relies on the accuracy of data entry on ClinicalTrials.gov, which is, however, currently the most widely used database for clinical study registration and assesses study details completely as required according to the International Committee of Medical Journal Editors.

- Furthermore, with respect to the missing publications from 32 studies in our analysis, we could neither identify why those remained unpublished nor what were the barriers towards the rapid publication of study results faced by the investigators, as we did not receive answers from the respective principal investigators or study sponsors after having contacted them.

\section{BACKGROUND}

Acute pulmonary failure in infancy and later childhood still accounts for a considerable mortality rate on paediatric and neonatal intensive care units. ${ }^{12}$ In that respect, invasive mechanical ventilation (MV) is a vital indication for severe loss of pulmonary function, ${ }^{3}$ but it ironically inflicts additional damage to 
pulmonary structures-referred to as ventilator-induced lung injury (VILI) - and thereby counteracts pulmonary healing. ${ }^{4}$

However, the paediatric intensivist must consider thatcompared with adults-the clinical entity of VILI is still not entirely characterised for the paediatric population. ${ }^{5}$ VILI is an established concept in newborn pulmonology, as it can induce a chronic condition termed bronchopulmonary dysplasia (BPD) ${ }^{6}$ But older children are also susceptible to harmful MV measures ${ }^{78}$ and paediatric VILI still lacks a uniform definition. ${ }^{59}$ Current preclinical literature suggests age-dependent differences in pulmonary sensitivity and reaction to harmful $\mathrm{MV}^{5}$ Results from animal studies indicate an inverse correlation between age and VILI susceptibility. ${ }^{10-12}$ An age-dependent VILI susceptibility might also be assumable for humans but this still remains to be further investigated by translational research. ${ }^{13}$ A careless transfer of VILI knowledge derived from studies in adult patients to mechanically ventilated children must be seen critical. ${ }^{14}$

As evidence-based clinical decision-making for mechanically ventilated children and those children with manifest VILI depends on reliable data from clinical studies, we must increase evidence in this field. Such clinical studies must address important clinical aspects in the comprehensive care for children under MV who are at risk ofor already suffering from - VILI: like mechanical and technical issues of $\mathrm{MV},{ }^{15}$ drug application during $\mathrm{MV},{ }^{16-23}$ diagnostics to assess ventilation intensity, weaning and follow-up ${ }^{1524-30-}$ but they should also focus on probable differences in age-related susceptibility to $M \mathrm{M}^{5}$

However, besides the need for more clinical studies on paediatric MV and VILI, selective reporting of clinical study results might introduce publication bias and unequal age representation in already published studies might introduce an additional selection bias into the field. Especially publication bias is considered a common problem in medical science and refers to the selective publication of clinical studies with significant differences in study outcomes and selective non-publication of studies with negative results. ${ }^{31}$ Publication bias might considerably affect evidence-based decision-making in patient care. Therefore, in 2004, the International Committee of Medical Journal Editors (ICMJE) have required all clinical studies to be registered prior to publication and the Food and Drug Administration (FDA) have stated in their Amendment Act (FDAAA) from 2007 that registered clinical studies should have publicly available results not later than 12 months after study completion. As the current literature shows, however, unselective reporting of study results in paediatrics must still be considered. ${ }^{32-34}$

Therefore, publication bias might also be present in clinical studies on paediatric MV and VILI and thereby might affect evidence-based decision-making. However, it has not yet been analysed in that high priority research field. Therefore, we designed this study as a first assessment of the current publication status of registered and completed clinical studies on MV and VILI in neonates and children from 1990 to 2017, including an analysis of age representation and primary focus on specific research questions.

\section{METHODS}

The proportion of published and unpublished study results of clinical studies on paediatric invasive MV and VILI registered as completed on ClinicalTrials.gov was determined.

\section{ClinicalTrials.gov database query and inclusion criteria}

www.clinicaltrials.gov was accessed through the internet. We used 'VILI', 'ventilator-associated lung injury', 'chronic lung injury', 'BPD', 'volutrauma', 'barotrauma', 'MV' and acute respiratory distress syndrome, 'ARDS', as primary search terms and focused on the advanced selection parameters 'completed studies' and 'child'. The advanced selection parameter 'child' included patients with an age ranging from 0 to 17 years. We downloaded the acquired data and checked for plausibility and duplicates manually (figure 1). We did not restrict the time frame for start of study or completion regarding the inclusion of studies in the analysis. General inclusion criteria for studies were defined as: studies enrolling children on invasive MV, studies enrolling children with pulmonary disease which is clearly associated with mechanical damage by previous or ongoing invasive MV in terms of VILI.

\section{Exclusion criteria}

To specifically assess MV in association with VILI, we excluded all studies, which did not address invasive MV at all and which focused on primary prevention of MV, on ventilator-associated pneumonia, on home ventilation or on studies with a primary focus on extracorporeal membrane oxygenation (ECMO). All studies included in our analysis have been published in English, however, publication languages other than English were no exclusion criterium.

\section{Items of analysis}

We analysed the remaining studies according to the following continuous or categorical study variables: patient age, public availability of study results, the time between completion of the study and public availability of results in months, patient enrolment, type of sponsor, study design. If numbers between ClinicalTrials.gov entries and peer-reviewed publications were inconsistent, we considered the data in the peer-reviewed publications as accurate. Patient age was categorised into three subgroups after evaluating the age representation pattern in the studies included in our analysis: below 1 year, between 1 and 14 years, above 14 years. This categorisation was chosen because many studies on neonates also included children up to 1 year of age. The cut-off at 14 years was set because some studies in our analysis enrolled 
search for registered, completed VILI trials in children

at ClinicalTrials.gov applying the following search terms:

- Bronchopulmonary Dysplasia $(\mathrm{N}=72)$

- Chronic lung disease $(N=173)$

- Mechanical Ventilation (=82)

- Barotrauma $(\mathrm{N}=2)$, Volutrauma $(\mathrm{N}=6)$

- $\operatorname{ARDS}(\mathrm{N}=154)$

- Ventilator-induced lung Injury $(N=85)$

- Ventilator-associated lung injury $(\mathrm{N}=18)$

$\mathbf{N}=\mathbf{5 9 0}$

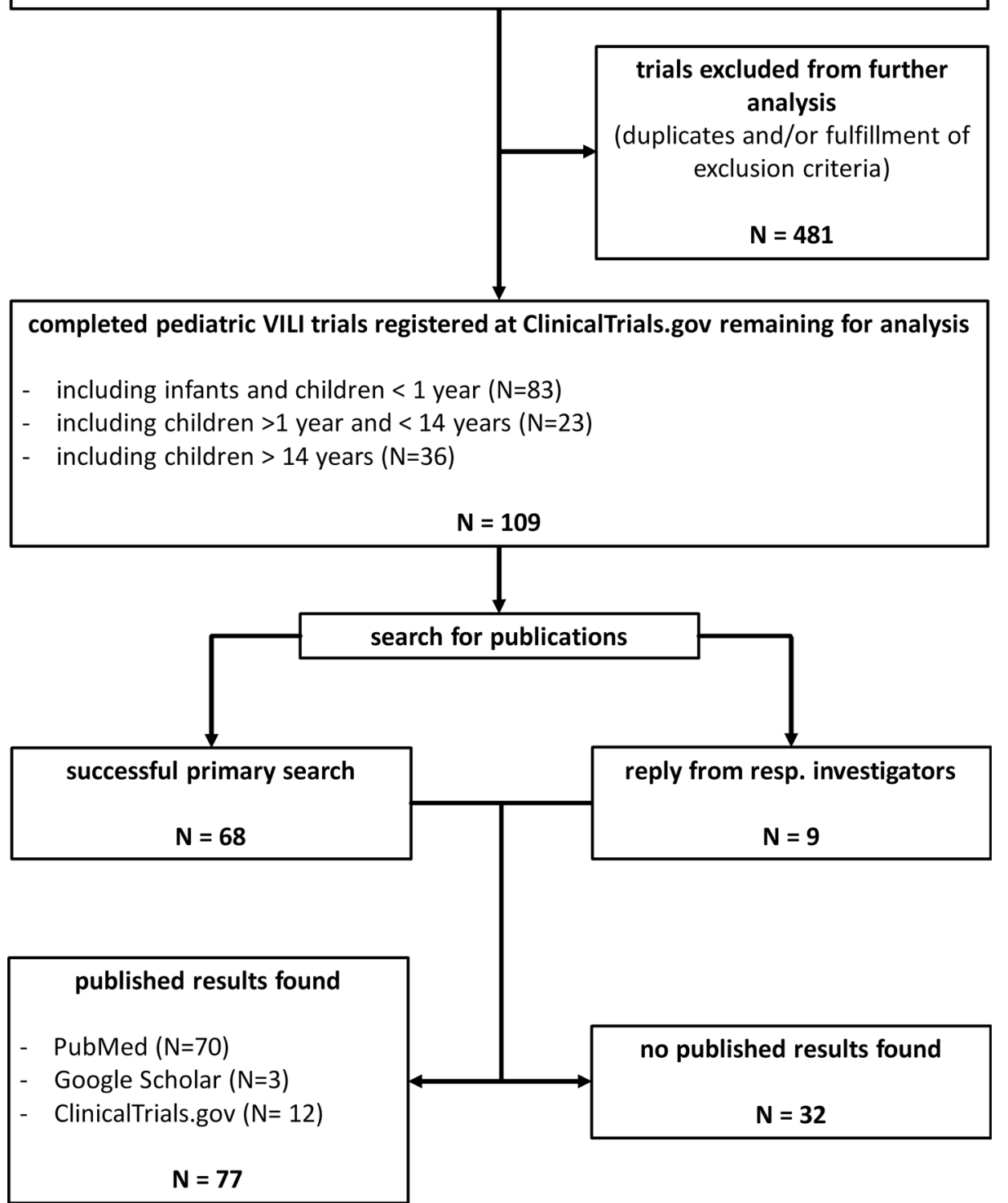

Figure 1 Study flow diagram. Identification of published and unpublished clinical studies registered on ClinicalTrials.gov on paediatric invasive mechanical ventilation and VILI. ARDS, acute respiratory distress syndrome; VILI, ventilator-induced lung injury.

adult patients in addition to children, but most of those studies did not include children below 14 years of age.

In addition, we stratified studies into five research topic subgroups according to their respective study focus or research question, thereby addressing important clinical aspects in paediatric MV and VILI care (mentioned in the Introduction section), which were: (1) biophysical/ mechanical aspects of ventilation, (2) drug application during MV to counteract VILI, (3) diagnostic issues (4) weaning and extubation success and (5) follow-up studies. Because of a particular significance in VILI research, studies assessing anti-inflammatory agents were analysed 
separately as a subgroup of drug studies. Studies that could not be attributed to one of the five research topic subgroups named above were assigned to the group 'miscellaneous' (online supplementary table 1).

We assigned follow-up studies to the age group(s) within which the MV event took place. Studies on extubation failure were included and assigned to the subtopic 'weaning'. One study on ECMO was included (NCT01423864) as MV parameters were primary study outcome measures. Studies were assigned to 'drug application' if drugs had been given during MV and primary or secondary readout parameters were for example effect on ventilation parameters or patient outcome. Studies were assigned to 'diagnostic issues', when they focused on a method to measure the adequacy of ventilation intensity or the pulmonary reaction towards invasive MV, for example by detecting inflammatory markers or physical pulmonary parameters like compliance during MV. (More information of assignment of studies to different research topic subgroups: see online supplemental material).

We assigned studies to more than one of the abovelisted age groups and research topic subgroups of MV and VILI research, if applicable.

\section{Search for respective publications}

We screened the major trial and literature databases for publications corresponding to the analysed studies in the following order: ClinicalTrials.gov, PubMed, Google Scholar. If no respective publication could be identified, we contacted the respective principal investigators or sponsors directly and asked them to provide us, if available, with the public study results. If study results were published on PubMed, we did not further search for them on Google Scholar (see figure 1).

\section{Patient and public involvement}

Patients or public were not involved.

\section{Statistical analysis}

We calculated time to publication as the difference in months between the date of publication and date of completion. We applied standard methods of descriptive statistics. We did not impute missing data. All calculations were performed with SAS Enterprise Guide V.5.1 (SAS) and GraphPad Prism V.7.01 (GraphPad Software, California, USA). Strengthening the Reporting of Observational Studies in Epidemiology criteria were applied for design and analysis of this cross-sectional study. ${ }^{35}$ Close of the database was 14 September 2017.

\section{RESULTS}

\section{Overall publication status of completed studies and study} participants (enrolment)

We identified $n=109$ registered and completed studies addressing paediatric invasive MV and VILI on ClinicalTrials.gov with a total enrolment of 22233 study participants (see figure 1, table 1). $\mathrm{n}=77$ out of those $(71 \%)$ had been published (enrolment: 18647 study participants), $n=32$ (29\%) were unpublished (enrolment: 3586 study participants) (table 1). The oldest study found in our search had been completed in 1990 (see figure 2). The investigated studies had a median size of 87 (IQR 30-240.5; range: 6-2449) patients. Published studies had a median size of 92 (IQR 30-327; range: 6-2449) patients whereas unpublished studies had a median size of 56 (IQR 39-164,5; range: 15-1000) patients. The year of completion ranged from 1990 to 2017. $\mathrm{n}=80$ studies (73\%) had an interventional study design and $n=59$ $(74 \%)$ out of those had been published. $\mathrm{n}=65$ interventional studies were randomised controlled trials (60\% out of 109 studies) and $n=45$ out of those had been published. The published randomised controlled trials contained data from $n=13493$ study participants compared with $\mathrm{n}=5154$ study participants from published non-randomised studies. There were $n=6$ phase 1 studies, $\mathrm{n}=20$ phase 2 studies, $\mathrm{n}=35$ phase 3 studies and $\mathrm{n}=3$ phase 4 studies.

Table 1 shows number, publication status and patient enrolment of registered and completed studies on paediatric MV and VILI. Studies were assigned to multiple research study subtopics if applicable.

\section{Time-to-public availability of results}

Figure 2 shows the number of studies by year of completion. The median time from study completion to public availability of research results, in general, was 22 months (IQR 12.8-41.5) with a range from 0 to 103 in general (figure 3 ). FDAAA $^{36}$ became effective on $27^{\text {th }}$ September 2007. Figure 3 represents time to publication of study results in months by year of completion. More recent studies tended to be published earlier. Publication time in months accumulated near the 12 months line as mandated by the FDAAA (figure 3). Seven studies had been completed within 12 months before the closure of our database (14 September 2017) and six of them have been published already.

\section{Pattern of research study subtopics}

Forty clinical studies (37\%) addressed drug application during MV to counteract VILI and 32 clinical studies (29\%) addressed biophysical and technical issues of MV to optimise clinical outcome. We found diagnostic issues during $\mathrm{MV}$, weaning and extubation success as well as follow-up assessment to be addressed by $16(15 \%)$, $11(10 \%)$ and $12(11 \%)$ clinical studies, respectively (table 1).

\section{Publication status by research study subtopic}

Publication status of studies assigned to one or more of the five research topic subgroups of MV and VILI research ranged from $55 \%$ (weaning and extubation success) to 83\% (drug application during MV to counteract VILI). Publication status of randomised studies assigned to one or more of the five research topic subgroups ranged from $50 \%$ (diagnostic issues) to $82 \%$ (drug application during 


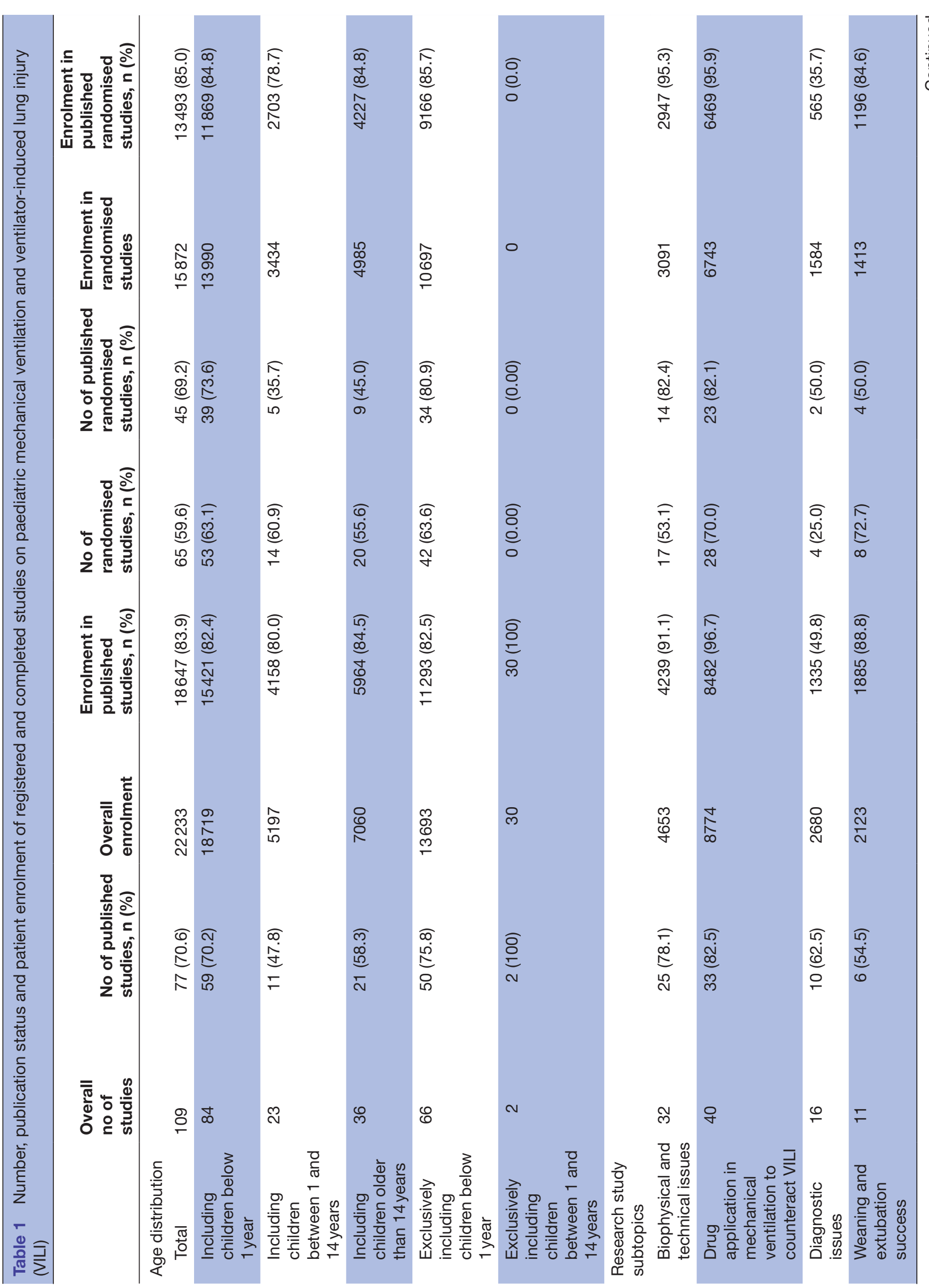




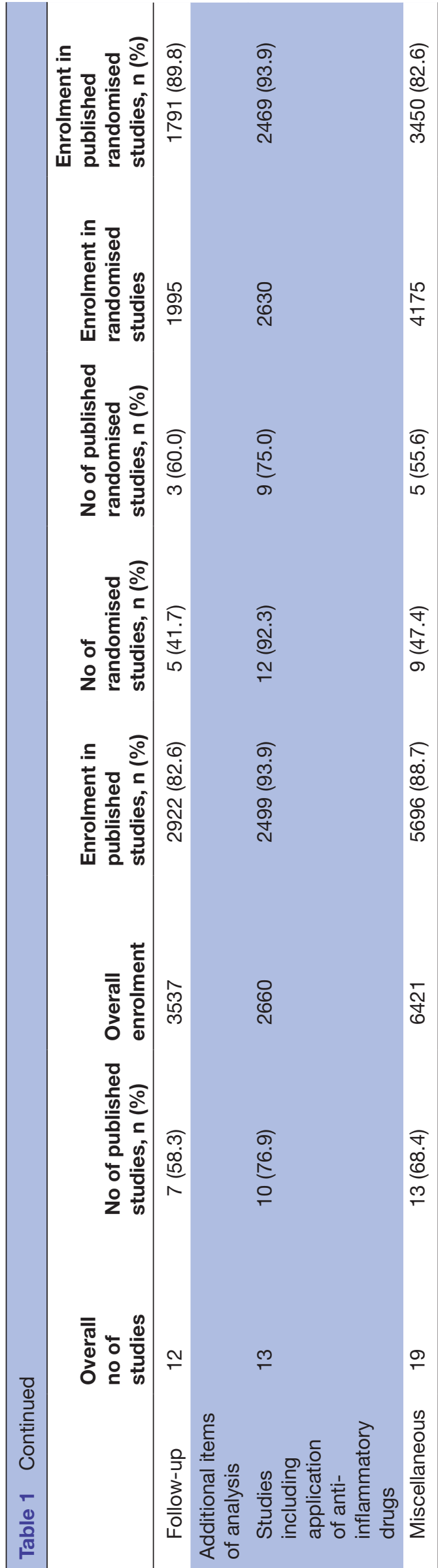

MV to counteract VILI). Table 1 summarises the distribution and publication status of studies by scientific research topic subgroup in paediatric MV. Online supplementary table 1 shows topics of 'miscellaneous study topics' in children.

\section{Anti-inflammatory drugs to counteract VILI}

We identified $n=13$ studies, which addressed the effect of anti-inflammatory drugs on the improvement of respiratory mechanics and/or on VILI genesis (study titles are listed in online supplementary table 2). Seventy-seven per cent of those $n=13$ studies which assessed anti-inflammatory drugs during MV had been published overall. Of those, almost all $(90 \%)$ had a randomised design. $n=10 / 13$ included children younger than 1 year of age. $n=9 / 13$ studies focused on the application of glucocorticoids. $\mathrm{n}=7 / 9$ studies on glucocorticoids had been performed in infants. $n=4 / 13$ studies on anti-inflammatory drugs included children older than 1 year of age and $n=2$ out of those showed positive effects of the investigated therapy on pulmonary function parameters (online supplementary table 2 ).

\section{Age and gender representation in clinical studies}

$\mathrm{n}=66 / 109$ studies had enrolled children below 1 year of age exclusively (table 1 ). The distribution of subtopics in studies including children with an age below 1 year is shown in figure $4 . \mathrm{n}=84 / 109$ studies enrolled both children below 1 year of age and older children (table 1). $n=2 / 109$ studies exclusively studied children with an age between 1 and 14 years (table 1). Further details including overall publication status and studies with randomised design are available in table 1 . A total of $n=106$ studies included both sexes whereas $n=3$ studies included male study participants exclusively.

\section{Study sponsors}

$\mathrm{n}=14$ studies had been sponsored or cosponsored by the industry and $n=12(86 \%)$ out of those have been published. All other studies had either been mainly sponsored by academia or the US National Institute of Health. $\mathrm{n}=65(68 \%)$ out of those have been published.

\section{DISCUSSION}

Our study revealed that publication bias in clinical paediatric invasive MV and VILI research may be present and would arise from unpublished data. Furthermore, there was a skewed distribution of investigated paediatric age groups towards patients below 1 year of age. This consequently would have an impact on the distribution of research study subtopics and, thereby, might introduce an additional selection bias in the field.

We found that $29 \%$ of all registered completed studies on paediatric invasive MV and VILI remained unpublished. These studies contained data from 3586 patients, which is $16 \%$ of the total amount of 22233 enrolled study participants. However, it is noteworthy that one of the 
A

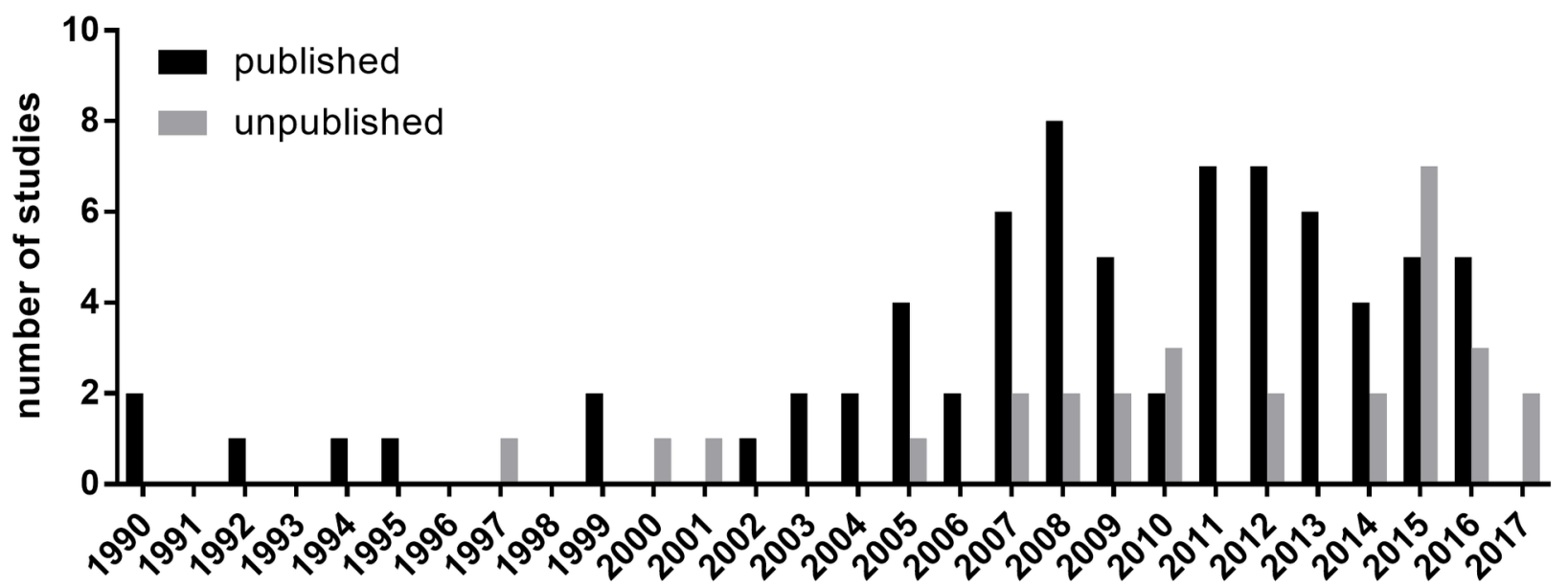

year of trial completion

B

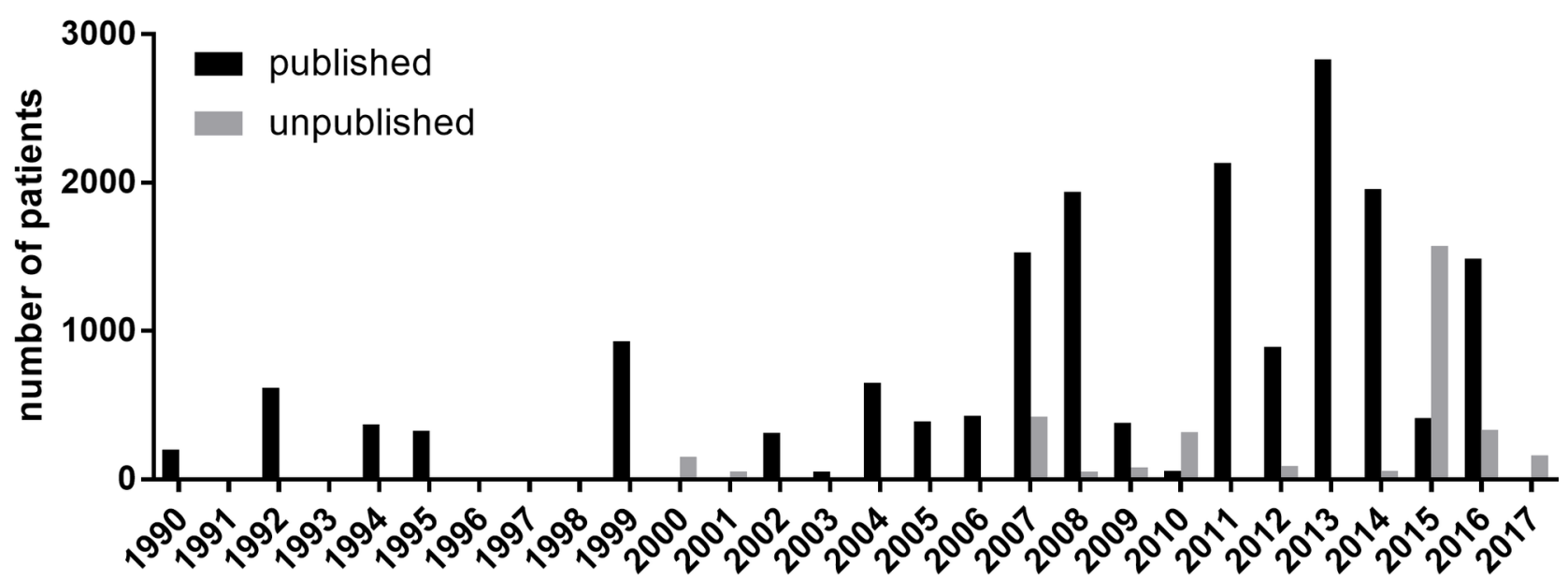

year of trial completion

Figure 2 Published and unpublished studies on paediatric invasive mechanical ventilation and ventilator-induced lung injury. (A) Shows the number of studies by year of completion. (B) Shows the number of patients by year of completion.

unpublished studies included 1000 patients. Yet, without taking this single study into our analyses, still, about $12 \%$ of the total patient enrolment would be unaccounted for due to unpublished study results. Furthermore, $69 \%$ of all randomised interventional studies have been published. This would imply that there might be a risk of publication bias arising from missing public availability of study results in the field. Publication bias would also affect research topic subgroups of MV, such as biophysical and technical issues, drug application during MV to counteract VILI, diagnostic issues, weaning and extubation success and follow-up.

Song et al estimated that approximately half of all clinical studies remain unpublished. They found that non-submission of studies was the main reason behind missing public study results. ${ }^{37}$ As a first measure to provide transparency, the ICMJE addressed the general problem of selective reporting of clinical study data in $2004^{33}$ and required mandatory registration of studies as a prerequisite for publication in member journals. ${ }^{38}$ Similar to that, the AllTrials campaign, supported by major scientific institutions like the Cochrane Collaboration, PLOS and BMJ, was started in 2003 as a petition that calls for all past and present trials to be registered and published. ${ }^{39} 40$ Furthermore, the FDA established an FDAAA in 2007, ${ }^{36}$ which suggests that clinical study results shall be published within 12 months after completion of the study. In our analysis, there seems to be a positive impact of the FDAAA on the timely availability of clinical study results in paediatric MV and VILI research, as indicated in figure 3 by 


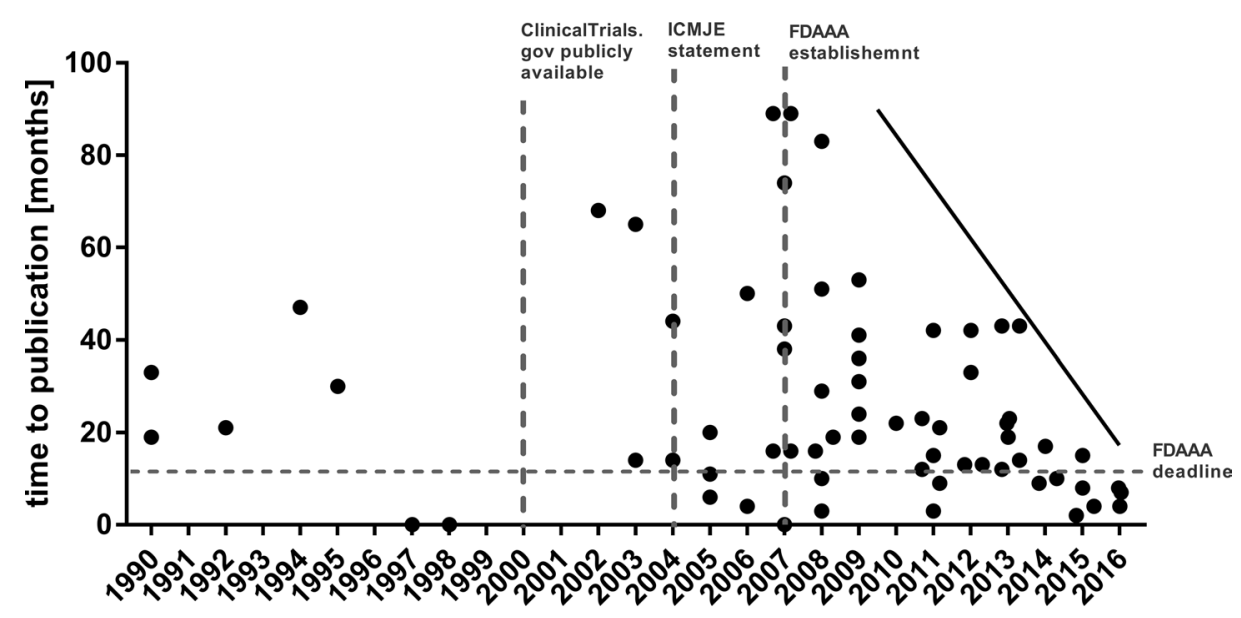

year of trial completion

Figure 3 Time-to-public availability of study results. (A) Time-to-public availability of results in months by year of study completion. Each dot represents one published study. Studies completed less than 12 months before the closure of our database were therefore not included in this figure. ${ }^{36} 41$ FDAAA, Federal Drug Administration Amendment Act; ICMJE, International Committee of Medical Journal Editors.

the accumulation of time-to-publication dots near the 12 months threshold line in more recent studies. A trend towards improvement in terms of timely, pubic availability of results exists also in other areas of paediatric medicine, such as epilepsy, autism and liver transplantation, even if a considerable amount of study data from registered and completed studies is still missing today. ${ }^{32-3441}$

In our study, the age representation in studies on paediatric MV and VILI was skewed towards patients below 1 year of age which had an impact on the distribution of investigated research questions or research topics (table 1, figure 4 ). In this age group, the most abundantly investigated study subtopic was the prevention of pulmonary damage via evaluating lung-protective ventilation mechanics and periventilatory drug applications. Thus, the over-representation of clinical studies focusing on the age group below 1 year distinctly impacts the distribution of research subtopics in paediatric clinical VILI research in general: about two-thirds of all investigated studies addressing biophysical aspects and ventilation techniques were performed in children younger than 1 year (figure 4 ). Similar to that, there were 40 studies on drug applications during MV and 34 out of those were performed exclusively in children below 1 year of age with a focus on the traditional adjunctive therapies surfactant and inhalative nitric oxide. The hazardous impact of extensive MV on pulmonary structures is well known and established in the neonate, but it is not for older children. ${ }^{5}$ According to the literature, it is assumable that children presumably react differently to intense volume overload compared with adults. ${ }^{5}$ Therefore, we conclude from our results and in accordance with the current scientific consensus, ${ }^{9}$ that there is an urgent need for more interventional as well as observational clinical studies on VILI prevention

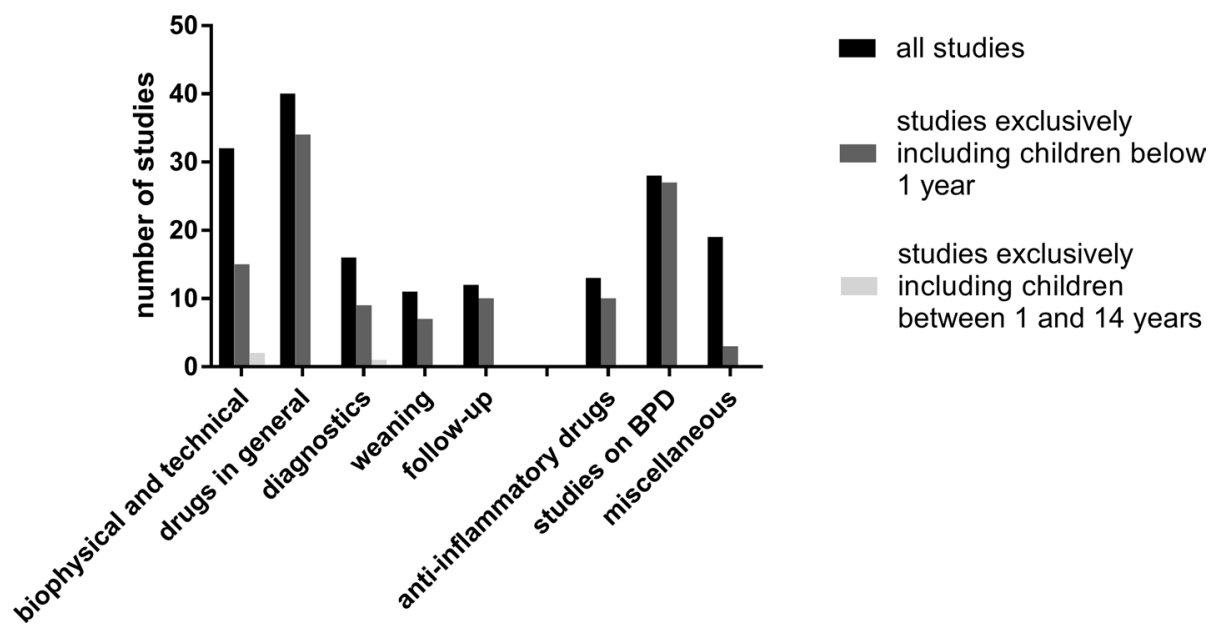

Figure 4 Research topic subgroups of completed registered and published studies on paediatric invasive mechanical ventilation and ventilator-induced lung injury. The over-representation of completed clinical studies exclusively focusing on children below 1 year of age impacts the overall distribution of research topic subgroups in paediatric mechanical ventilation research. BPD, bronchopulmonary dysplasia. 
and follow-up after MV in small and school age children. ${ }^{5}$ These studies should clarify our understanding of VILI incurrence as well as the underlying pathophysiology in children, generate more clinically relevant evidence and-thereby-avoid extrapolation of knowledge from adult populations to children. To reach that goal, probably, multicentral approaches might be necessary to achieve sufficient enrolments because of the presumably lower incidence of VILI in that age group compared with neonates or adults. ${ }^{5}$

A comprehensive analysis of research subtopics in paediatric invasive MV and VILI revealed that most completed registered clinical studies addressed biophysical and technical aspects of MV, drug usage to counteract VILI during MV, diagnostics, weaning and follow-up. Furthermore, we found miscellaneous study subtopics, for example, sedation, nutrition or structural aspects of intensive care. In the analysed studies, biophysical, technical and drug-based measurements distinctly overweighed other research topic subgroups like follow-up studies. This illustrates that clinical research in paediatric invasive MV distinctly focusses on VILI prevention in the first place.

With respect to VILI prevention, clinical implications arising from the inflammatory genesis of VILI must be considered. Current preclinical research results highlight the central role of the inflammatory reactions in pulmonary tissue during mechanically overdistention as the basis of VILI, suggesting a certain importance of anti-inflammatory drug applications during $\mathrm{MV}^{16-18}$ Clinical research provides already promising results in neonates and adults which show that anti-inflammatory drugs - such as corticosteroids - could reduce the severity or even prevent the occurrence of VILI when applied during MV. ${ }^{20-23}{ }^{42-46}$ In our study, a skewed age representation was present in clinical studies focusing on anti-inflammatory drug applications during invasive MV. We found that $77 \%$ of studies on anti-inflammatory drugs to prevent VILI were performed in neonates. In contrast, only three clinical studies on anti-inflammatory drugs during MV were conducted in children older than 1 year of age. Two of those, one on glucocorticoids and one on the anti-inflammatory clara cell protein 10 , resulted in an improved pulmonary function during ventilation. Therefore, an increased focus should be put on anti-inflammatory drugs in mechanically ventilated children older than 1 year of age in future clinical studies.

This work has several limitations. Our analysis relies on the accuracy of data entry into ClinicalTrials.gov, which provides the most widely used database for registered clinical studies and assesses study details completely as required according to the ICMJE. ${ }^{38}$ Clinical trial databases other than ClinicalTrials.gov were not considered. As the ratio of published to unpublished studies was one major aspect of analysis in our work, we made all efforts to avoid missing any publication by searching the two major medical literature databases PubMed and Google Scholar, and-if unsuccessful-by contacting investigators or institutions directly. With respect to the missing publications from 32 studies in our analysis, we could neither identify the reasons why those remained unpublished nor the barriers towards the rapid publication of study results faced by the investigators, as we did not receive answers after having contacted the respective principal investigators of study sponsors directly. We might speculate, that some authors could or would not publish their results due to limitations of methodology, analyses or interpretation of the results. A barrier towards timely publication as recommended by the FDAAA might arise from repeated rejections and/or required revision work as demanded by journal reviewers, however, study results can easily be posted on the ClinicalTrials.gov website. In addition, publication status of studies registered as completed near September 2017 (closure of our database) must be interpreted carefully. Figure 3 shows that the maximum time to publication between 2015 and 2017 was about 2 years, which might implicate, that some studies, which had been completed in those years, might have been published after September 2017 and are thus included as 'unpublished' in our analysis. Our data show that time-to-public availability of study results tended to centre around 12 months in more recent studies, which is indicated by the accumulation of dots at the 12 months threshold line in figure 3. However, we cannot exclude that some recent studies, which are currently unpublished, might probably get published in the future after the closure of our database and would then appear as dots above the diagonal line at the right end of the time axis in figure 3. This makes the interpretation of the median time to publication difficult. Further, ClinicalTrials.gov was made public in February 2000 and the ICMJE requirement to register all studies prior to publication was stated in September 2004. These dates might influence the study registration pattern and-more importantly-the respective publication status. Furthermore, it would have been interesting to analyse publication status of clinical studies in paediatric or neonatal ARDS as defined by the Pediatric Acute Lung Injury Consensus Conference group and the Montreux definition. ${ }^{247}$ Despite the scientific and clinical relevance of this issue, there is a lack of data. We found only 2 out of 109 studies with a specific focus on ARDS.

\section{CONCLUSION}

In conclusion, we want to raise the awareness, that one-third of clinical studies in paediatric MV and VILI registered as completed on ClinicalTrials.gov remained unpublished and contained data on 3586 study participants. This might introduce publication bias by selective reporting of study data to the field and thereby affect evidence-based clinical decision-making. Overall median time-to-public availability of study results was longer than the deadline of 12 months mandated by the FDAAA of 2007. Important and clinically relevant study subtopics were represented in the research questions investigated in paediatric MV and VILI. The study population was skewed towards children younger than 1 year which indicates 
that there might be an additional selection bias in the field and therefore a substantial need for clinical VILI research in older children. While insufficient trial quality will be accounted for in excellent systematic reviews, ${ }^{48}$ timely availability of data derived from clinical studies on paediatric MV and VILI can improve methodology for future clinical studies by learning from previous projects including unsuccessful ones. In addition, transparency in clinical research has the potential to improve patient care, prevent further children from being exposed to repeated and potentially unnecessary research and diversify our understanding of artificial ventilation mechanics and pathophysiology in children.

\section{Author affiliations}

${ }^{1}$ Department of Pediatrics I, University Children's Hospital Heidelberg, Heidelberg, Germany

${ }^{2}$ Institute for Physiology and Pathophysiology, University Children's Hospital Heidelberg, Heidelberg, Germany

${ }^{3}$ Department of Neonatology, University Children's Hospital Heidelberg, Heidelberg, Germany

${ }^{4}$ Clinic for Neonatology, University Medical Center Mannheim, Mannheim, Germany ${ }^{5}$ Pediatric Neurology and Metabolic Medicine, Center for Pediatric and Adolescent Medicine, University Hospital Heidelberg, Heidelberg, Germany

Contributors CP designed and performed research, analysed the data and wrote the manuscript. SK performed research and analysed the data. CP and SK contributed equally to this work. NR and TS analysed the data. BT and GFH designed research and revised the manuscript. MR designed research, analysed the data and revised the manuscript.

Funding The authors have not declared a specific grant for this research from any funding agency in the public, commercial or not-for-profit sectors.

Competing interests None declared.

Patient consent Not required.

Provenance and peer review Not commissioned; externally peer reviewed.

Data sharing statement All data generated or analysed during this study are included in this published article and its online supplementary files. The respective clinical studies analysed in this study can be accessed via ClinicalTrials.gov. Search criteria were given in the methods section of this manuscript.

Open access This is an open access article distributed in accordance with the Creative Commons Attribution Non Commercial (CC BY-NC 4.0) license, which permits others to distribute, remix, adapt, build upon this work non-commercially, and license their derivative works on different terms, provided the original work is properly cited, appropriate credit is given, any changes made indicated, and the use is non-commercial. See: http://creativecommons.org/licenses/by-nc/4.0/.

\section{REFERENCES}

1. Flori HR, Glidden DV, Rutherford GW, et al. Pediatric acute lung injury. Am J Respir Crit Care Med 2005:171:995-1001.

2. Pediatric Acute Lung Injury Consensus Conference Group. Pediatric acute respiratory distress syndrome: consensus recommendations from the Pediatric Acute Lung Injury Consensus Conference. Pediatr Crit Care Med 2015;16:428-39.

3. Matthay MA, Ware LB, Zimmerman GA. The acute respiratory distress syndrome. J Clin Invest 2012;122:2731-40.

4. Slutsky AS. Ventilator-induced lung injury: from barotrauma to biotrauma. Respir Care 2005;50:646-59.

5. Kneyber MC, Zhang H, Slutsky AS. Ventilator-induced lung injury. Similarity and differences between children and adults. Am J Respir Crit Care Med 2014;190:140708115209002.

6. Coalson JJ. Pathology of bronchopulmonary dysplasia. Semin Perinatol 2006;30:179-84.

7. Erickson S, Schibler A, Numa A, et al. Acute lung injury in pediatric intensive care in Australia and New Zealand: a prospective, multicenter, observational study. Pediatr Crit Care Med 2007;8:31723.
8. Plötz FB, Vreugdenhil HA, Slutsky AS, et al. Mechanical ventilation alters the immune response in children without lung pathology. Intensive Care Med 2002;28:486-92.

9. Kneyber MC. Ventilator-induced lung injury: does it occur in children? Minerva Anestesiol 2018;84:626-631.

10. Smith LS, Gharib SA, Frevert CW, et al. Effects of age on the synergistic interactions between lipopolysaccharide and mechanical ventilation in mice. Am J Respir Cell Mol Biol 2010;43:475-86.

11. Schouten LR, Helmerhorst HJ, Wagenaar GT, et al. Injurious ventilation has an age-dependent affect on the pulmonary renin-angiotensin system in LPS-challenged rats. Critical Care 2014;18(Suppl 1):P335.

12. Schouten LR, Helmerhorst HJ, Wagenaar GT, et al. Age-dependent changes in the pulmonary renin-angiotensin system are associated with severity of lung injury in a model of acute lung injury in rats. Crit Care Med 2016;44:e1226-e1235.

13. Smith LS, Zimmerman JJ, Martin TR. Mechanisms of acute respiratory distress syndrome in children and adults: a review and suggestions for future research. Pediatr Crit Care Med 2013;14:63143.

14. Schouten LR, Schultz MJ, van Kaam AH, et al. Association between maturation and aging and pulmonary responses in animal models of lung injury: a systematic review. Anesthesiology 2015;123:389-408.

15. Chiumello D, Carlesso E, Cadringher $P$, et al. Lung stress and strain during mechanical ventilation for acute respiratory distress syndrome. Am J Respir Crit Care Med 2008;178:346-55.

16. Chiumello D, Pristine G, Slutsky AS. Mechanical ventilation affects local and systemic cytokines in an animal model of acute respiratory distress syndrome. Am J Respir Crit Care Med 1999;160:109-16.

17. Chapman KE, Sinclair SE, Zhuang D, et al. Cyclic mechanical strain increases reactive oxygen species production in pulmonary epithelial cells. Am J Physiol Lung Cell Mol Physiol 2005;289:L834-L841.

18. Kobayashi K, Tanaka M, Nebuya S, et al. Temporal change in IL-6 mRNA and protein expression produced by cyclic stretching of human pulmonary artery endothelial cells. Int J Mol Med 2012;30:509-13

19. Fan E, Villar J, Slutsky AS. Novel approaches to minimize ventilatorinduced lung injury. BMC Med 2013;11:85.

20. Slutsky AS, Ranieri VM. Ventilator-induced lung injury. N Engl J Med Overseas Ed 2013;369:2126-36.

21. Uhlig S, Uhlig U. Pharmacological interventions in ventilator-induced lung injury. Trends Pharmacol Sci 2004;25:592-600.

22. Ju YN, Yu KJ, Wang GN. Budesonide ameliorates lung injury induced by large volume ventilation. BMC Pulm Med 2016;16:90.

23. Papile LA, Tyson JE, Stoll BJ, et al. A multicenter trial of two dexamethasone regimens in ventilator-dependent premature infants. N Engl J Med 1998;338:1112-9

24. Singer L, Yamashita T, Lilien L, et al. A longitudinal study of developmental outcome of infants with bronchopulmonary dysplasia and very low birth weight. Pediatrics 1997;100:987-93.

25. Chiumello D, Chidini G, Calderini E, et al. Respiratory mechanics and lung stress/strain in children with acute respiratory distress syndrome. Ann Intensive Care 2016;6.

26. Chang YS, Ahn SY, Yoo HS, et al. Mesenchymal stem cells for bronchopulmonary dysplasia: phase 1 dose-escalation clinical trial. $J$ Pediatr 2014:164:966-72.

27. Parikh NA, Kennedy KA, Lasky RE, et al. Neurodevelopmental outcomes of extremely preterm infants randomized to stress dose hydrocortisone. PLoS One 2015;10:e0137051.

28. Godet TJ, Chabanne R, Marin J, et al. Identification of Criteria Associated with Extubation Failure in Brain-Injured Patients. Elaboration of a Prognostic Score. GODWEAN Study. 2016 https://www.atsjournals.org/doi/abs/10.1164/ajrccm-conference. 2016.193.1 MeetingAbstracts.A5289

29. Fuller BM, Mohr NM, Miller CN, et al. Mechanical ventilation and ARDS in the ED. Chest 2015;148:365-74.

30. Onland W, De Jaegere APMC, Offringa M, et al. Systemic corticosteroid regimens for prevention of bronchopulmonary dysplasia in preterm infants. Cochrane Database Syst Rev 2017;86.

31. Jones PM. Publication bias in the anesthesiology literature: shifting the focus from the "positive" to the "truth". Can J Anaesth 2016;63:658-63.

32. Breil T, Wenning D, Teufel U, et al. An assessment of publication status of pediatric liver transplantation studies. PLoS One 2016;11:e0168251.

33. Lampert A, Hoffmann GF, Ries M. Ten years after the international committee of medical journal editors' clinical trial registration initiative, one quarter of phase 3 pediatric epilepsy clinical trials still remain unpublished: a cross sectional analysis. PLoS One 2016:11:e0144973. 
34. Mechler K, Hoffmann GF, Dittmann RW, et al. Defining the hidden evidence in autism research. Forty per cent of rigorously designed clinical trials remain unpublished - a cross-sectional analysis. Int $J$ Methods Psychiatr Res 2017;26.

35. Vandenbroucke JP, von Elm E, Altman DG, et al. Strengthening the Reporting of Observational Studies in Epidemiology (STROBE): explanation and elaboration. PLoS Med 2007;4:e297.

36. 110th Congress Public Law. Food and Drug Administration Amendments Act of 2007. 2007. https://www.gpo.gov/fdsys/pkg/ PLAW-110publ85/html/PLAW-110publ85.htm

37. Song F, Loke Y, Hooper L. Why are medical and health-related studies not being published? A systematic review of reasons given by investigators. PLoS One 2014;9:e110418.

38. De Angelis C, Drazen JM, Frizelle FA, et al. Clinical trial registration: a statement from the International Committee of Medical Journal Editors. N Engl J Med 2004;351:1250-1.

39. Brown T. It's time for alltrials registered and reported. Cochrane Database Syst Rev 2013(4):ED000057.

40. AllTrials.net. 2014 http://www.alltrials.net/find-out-more/aboutalltrials/ (accessed 22 Feb 2017).

41. Anderson ML, Chiswell K, Peterson ED, et al. Compliance with results reporting at ClinicalTrials.gov. $N$ Engl $J$ Med 2015;372:1031-9.
42. Santos $\mathrm{CC}$, Zhang $\mathrm{H}$, Liu M, et al. Bench-to-bedside review: Biotrauma and modulation of the innate immune response. Crit Care 2005;9:280-6.

43. Ghanta S, Leeman KT, Christou H. An update on pharmacologic approaches to bronchopulmonary dysplasia. Semin Perinatol 2013;37:115-23.

44. Onland $W$, Offringa $M$, van Kaam $A$. Late ( $\geq 7$ days) inhalation corticosteroids to reduce bronchopulmonary dysplasia in preterm infants. Cochrane Database Syst Rev 2017;8:CD002311.

45. Shah VS, Ohlsson A, Halliday HL, et al. Early administration of inhaled corticosteroids for preventing chronic lung disease in very low birth weight preterm neonates: In. Shah VS, ed. Cochrane Database of Systematic Reviews. Chichester,UK: John Wiley \& Sons, 2017.

46. Harrold J, Ali S, Oleszczuk M, et al. Corticosteroids for the prevention of bronchopulmonary dysplasia in preterm infants: an overview of Cochrane reviews. Evidence-Based Child Health: A Cochrane Review Journal 2013;8:2063-75

47. De Luca D, van Kaam AH, Tingay DG, et al. The Montreux definition of neonatal ARDS: biological and clinical background behind the description of a new entity. Lancet Respir Med 2017;5:657-66.

48. AllTrials.net. Myths and objections. 2014 http://www.alltrials.net/findout-more/faq/ (accessed 10 Jul 2018). 